

\section{A MOdERnidade dA ESCRAVIDÃo E 0 CAPITALISMO NORTE-AMERICANO}

BAPTIST, Edward E. A metade que nunca foi contada: a escravidão e a construção do capitalismo norte-americano. Rio de Janeiro e São Paulo: Paz e Terra, 2019. 551 p.

A metade que nunca foi contada é o segundo livro do historiador norte-americano Edward E. Baptist. Professor na Universidade de Cornell (Ithaca, NY), Baptist apresenta em seu novo trabalho, originalmente publicado como The Half Has Never Been Told, em 2014, os resultados de um longo percurso de pesquisa sobre a construção da fronteira escravista no sudoeste norte-americano no século XIX, expandindo um tema que já era o centro do seu primeiro livro monográfico, Creating a New South (2002).

O novo livro reconta a história dos Estados Unidos - em específico, a história econômica do capitalismo norte-americano, mas também sua história política -, procurando demonstrar, nas palavras expressas na conclusão, que a expansão da escravidão foi "a força motriz na história dos EUA entre a elaboração da Constituição e o início da Guerra Civil” (p. 521).

O título é extraído de um dos muitos relatos, utilizados no livro, de pessoas nascidas escravizadas antes da Guerra Civil (1861-1865) e que foram registrados por funcionários temporários do governo americano durante o New Deal, e refere-se ao silêncio sobre a história vivida e rememorada pelos antigos escravos. Mas, em um livro que explora a força das metáforas, a "metade" alude também à história invisibilizada pela narrativa oficial, uma porção substancial e não contada da trajetória do 
capitalismo que coloca o horror da escravidão no seu centro, uma narrativa das transformações profundas das circunstâncias do cativeiro racial e que representam o outro lado da "modernização" e "sucesso" econômico dos Estados Unidos.

O sólido volume, de mais de quinhentas páginas, é dividido em dez capítulos, cada um trazendo como título uma parte do corpo humano ou uma função corporal, alinhavados com a cronologia do regime escravista em seu apogeu e queda.

Os dois primeiros capítulos, intitulados "Pés, 1783-1810", e “Cabeças, 1791-1815”, focam o início do processo de expansão da escravidão no Sul, com o estabelecimento da lavoura de algodão no estado da Georgia, e que respondia à demanda crescente pelo produto pelas novas indústrias têxteis inglesas e domésticas. Os "pés em marcha dos escravizados" servem como ponto de partida para discutir o processo de migração forçada que marcou o período. A abertura da nova fronteira da escravidão - que retiraria, nos anos e décadas seguintes, milhões de pessoas vendidas das velhas áreas escravistas para a fronteira sempre mais dilatada do algodão - traçou caminhos "na terra, na política e na economia”, revelados pelas "pegadas que os escravos conduzidos, e aqueles que os conduziam, deixaram nos documentos e negócios da nação" (p. 29). Esse é um momento que também coincide com o estabelecimento das instituições políticas do país independente, fortemente comprometidas com a escravidão, e que reforçaram a criação de uma aristocracia agrária escravista que manteria por décadas uma influência desproporcional na condução política do país. Desde o início, Baptist mostra o quão ilusória é a ideia de uma divisão inconciliável entre o sul escravista e o norte livre, apontando - como faz seguidamente ao longo do livro - a interdependência entre a economia industrial e comercial do norte e a produção algodoeira sulina.

A revolução liderada por escravizados na colônia francesa de SaintDomingue, a guerra de 1812 com os ingleses e a subsequente aquisição do território da Louisiana das mãos dos franceses, que abarcava toda a margem ocidental do Rio Mississipi, proporcionaram as oportunidades e o espaço que a jovem república 
escravista precisava para expandir-se. A ironia de a revolta escrava mais bem sucedida da história ter dado fim às pretensões francesas na região e aberto as portas para a nova fase da escravidão não escapa a Baptist. As cabeças dos escravizados imobilizados pelas gargalheiras e negociados em Nova Orleans encontram-se com as cabeças dos novos empreendedores escravistas, conscientes dos seus interesses, que haviam aprendido as lições de Saint-Domingue, e tinham ao seu lado um governo federal pronto a intervir favoravelmente.

Os capítulos 3 e 4 - "Mão direita, 1815-1819” e "Mão esquerda, 18051861" - contrastam a mão violenta e dominadora dos senhores de escravos com a mão de trabalho e resistência dos escravizados. Em um período marcado pela transformação do algodão na commodity mais negociada do mundo (p. 129), a imperiosa “mão direita” dos empreendedores brancos assumia riscos e controlava firmemente não apenas os instrumentos de criação da nova economia escravista - com o dinheiro passando “de mão em mão” no comércio de mercadorias e seres humanos mas também operando a inovação tecnológica nos campos de algodão, as novas ferramentas financeiras e a “máquina de açoitar” da escravidão. As novas instituições bancárias que se desenvolveram no período, e o desenvolvimento de formas aperfeiçoadas de acesso ao crédito que articulavam firmemente a economia algodoeira às finanças internacionais, têm papel de relevo aqui, mostrando seus efeitos na transformação das “mãos” dos escravos não apenas e cada vez mais em uma mercadoria como qualquer outra, mas na principal garantia para novos créditos, que eram reinvestidos na expansão agrícola e na ampliação do mercado interno de escravizados após o fim do tráfico atlântico.

No quarto capítulo, Baptist argumenta contra a interpretação consolidada de que a expansão exponencial da produção que consolidou o "Império do Algodão" havia sido resultado da inovação tecnológica na colheita e da seleção de sementes para a plantação. Ao contrário, ele propõe, num dos argumentos chave do livro, que a principal inovação adotada pelos agricultores estava diretamente relacionada à "eficiência” na extração de exploração da mão de obra escravizada. Os empresários do algodão e 
da escravidão empregaram toda sua inventividade na construção do que, de acordo com Baptist, era um regime “completamente novo” de produção, com estrita contabilidade do volume das tarefas e "racionalização" do uso do tempo, vigilância contínua e, sobretudo, o uso sistemático da violência e da tortura para extrair o máximo de trabalho (e também da inventividade) dos escravizados. A "inovação na violência” se tornou a base da estrutura de produção "mais eficiente do mundo" (p. 160) e era chave do novo "sistema de cotas crescentes” (pushing system), que abriu um novo capítulo no processo de desumanização que caracterizava a escravidão, destruindo famílias, as relações afetivas e redes de solidariedade entre os escravizados, e tornando obsoletas as antigas estratégias de acomodação e negociação que existiam sob a “velha” escravidão.

Os capítulos 5 e 6 chamam-se, respectivamente, "Línguas, 1819-1824" e “Respiração, 1824-1835”. Seu foco está, mais uma vez, na experiência dos escravizados submetidos ao novo sistema de exploração escravista, que deslocava os "migrantes forçados” para a nova fronteira agrícola, colocando-os em competição uns com os outros. O "compromisso do Missouri”, de 1820, é o pano de fundo aqui. Ao demarcar os limites das áreas "livres" e aquelas de expansão da escravidão, também havia estabelecido na legislação um princípio que, apesar de debatido e contestado, manteve-se como um dos pilares da democracia americana até a Guerra Civil: o direito à propriedade escrava como princípio absoluto e a ideia de que o "direito de se expandir era igual ao direito da autopreservação" (p. 214).

Baptist mostra que a venda de pessoas escravizadas das velhas regiões escravistas do Chesapeake e das Carolinas para as novas fronteiras do algodão também permitiu que os lucros dessas transações financiassem novos empreendimentos e a diversificação de atividades em regiões como a Virginia e Maryland, no Velho Sul. O tráfico interno deu nova força à escravidão, fazendo desaparecer a esperança de que o fim do tráfico transatlântico faria com que a escravidão morresse por conta própria.

As memórias narradas pelas pessoas que viveram esse processo fornecem testemunho de primeira 
mão dessa nova fase da escravidão norte-americana e seu enorme impacto humano. Elas servem como os fios condutores que mantêm presa ao chão a "grande narrativa" de modernidade e inovação violentas, e do capitalismo racializado. Baptist articula as memórias dos ex-escravos com as cifras que emergem dos registros das vendas de escravizados em Nova Orleans, onde ele recupera parte da dinâmica do tráfico interno, o número de vezes que homens, mulheres e crianças trocaram de mãos, seus locais de origem e de destino. Em contraste com a imagem de uma relação marcada pelo paternalismo, o que se vê é um mercado impessoal, onde o investimento nos escravos é liquidado sem grandes preocupações sobre as consequências humanas dos negócios. A linguagem dos escravizados forneceria a interpretação que estes formulavam sobre o que acontecia: descreviam sua migração forçada como "roubo" (p. 252). O quadro que daí emerge reforça a imagem de uma escravidão mais tirânica.

Baptist preocupa-se em mostrar, contudo, que formas de solidariedade emergiram entre os escravizados, ligadas à religião e à tentativa de dar algum sentido às suas vidas sob as novas condições de degradação. A improvisação e a resiliência diante da diversidade têm um lugar importante aqui, e o papel inovador que a cultura negra viria a desempenhar na história norte-americana (e mundial, como lembra Baptist) se deixa antever, mesmo que de relance, na música dos escravizados, por exemplo. Baptist também recupera o papel ambíguo que a religião desempenha nesse contexto, sublinhando a coincidência entre a emergência do evangelismo revivalista, muitas vezes abraçado pelos próprios escravizados, e a expansão da escravidão, tendo influenciado revoltas escravas como a de Nat Turner em 1831, na Virgínia. Além disso, aponta a emergência de um movimento abolicionista consistente em meados dos anos 1830.

Os capítulos 7 e 8 do livro exploram os "dramas da masculinidade branca" e seus estragos sobre as vidas de homens e mulheres escravizados. As inflexões do verbo “foder” (fuck) - síntese da ação direta de homens brancos sobre a terra e os escravizados de ambos os sexos, e a relação entre os homens brancos 
- fornecem o eixo desses capítulos. A busca pelo lucro e o gosto pelo risco "lucrativo e desastroso" são reforçados pela cultura de violência da escravidão (aqui devidamente sexualizada na linguagem dos próprios atores sociais) que, nas palavras de Baptist, permitia "a dominação sem controle e prometia o cumprimento ilimitado do desejo irrestrito" do macho branco (p. 311).

Baptist revisita a "década democrática” (capítulo 7: “Semente, 18291837”), que foi como a historiografia identificou aépoca em que o ex-general Andrew Jackson ocupou a presidência dos Estados Unidos. O livro mostra como a expansão da cidadania branca, a "explosão econômica" (p. 290) e a mobilidade espacial e social que definiram o período eram inseparáveis do impulso de conquista territorial, com a guerra contra os indígenas e sua expulsão para os territórios do que mais tarde seria Oklahoma. A fronteira era, não por acaso, marcada pela violência, favorecida pela escravidão, com reflexos sobre a própria política "populista” apoiada por Jackson. A formação da "primeira democracia de massa na história do mundo” (p. 299) teria sido construída, de acordo com Baptist, como um "novo tipo de governo" baseado no "acesso igualitário dos homens brancos à masculinidade e à cidadania, privando todos os demais de direitos" do "igualitarismo da cidadania viril branca” (p. 303).

O recorte temporal do capítulo 8 (“Sangue, 1836-1844”) abarca o período que cunhou a expressão “Destino Manifesto” para descrever “o direito outorgado por Deus aos cidadãos brancos dos Estados Unidos de tomar o restante da América do Norte dos índios e dos mexicanos mestiços” (p. 391). A anexação violenta do Texas e outras disputas territoriais com o México, que levaram à anexação dos territórios do oeste norte-americano até a Califórnia, e os embates políticos sobre os limites da fronteira escravista deram substância a essa ambição conquistadora.

O centro do capítulo está em uma história financeira do negócio da escravidão, acompanhando as crises econômicas e de crédito que marcaram o período, e como sua resolução pela inovação das estruturas bancárias e das instituições financeiras deram novo impulso aos investimentos escravistas, aumentando sua eficiência 
financeira em termos de liquidez e solvência. Baptist mostra como as crises por que passou a cultura algodoeira, impactada pela flutuação dos preços, poderiam destruir os planos de grandeza dos homens brancos e suas famílias, mas elas tiveram um efeito verdadeiramente devastador sobre os escravizados e seus laços afetivos e familiares, vítimas de novas "migrações forçadas" que os havia "isolado e atomizado, roubando seu otimismo e ensinando-lhes a devastadora lição de que seus laços de sangue podiam ser quebrados em pedaços incognoscíveis” (p. 384). Ao contrário de ser ameaçada pela "modernidade" capitalista, a escravidão vivia um momento de expansão, e as lideranças políticas do sul defendiam que as práticas econômicas na região eram inteiramente adaptadas a uma economia de mercado.

O dois últimos capítulos do livro intitulados respectivamente "Costas, 1839-1850" e "Braços, 1850-1861" - lidam com a discrepância crescente entre o norte "livre" e industrializado e o sul "escravista” e agrário nas duas décadas anteriores à Guerra Civil. Baptist debate diretamente com a narrativa que costuma associar o rápido desenvolvimento industrial do norte ao seu etos individualista e a "engenhosidade" derivada do compromisso com o "trabalho livre". Ele argumenta que a indústria foi capaz de aproveitar de modo privilegiado o aumento de produtividade na colheita e processamento do algodão, permitindo um reinvestimento em máquinas, no pagamento dos operários e na expansão do consumo, enquanto o Sul aprofundava sua dependência à produção algodoeira. Com a associação do crescimento e da diversificação industrial do Norte à expansão da oferta do insumo barato produzido por braços escravizados, a criação da nova classe operária branca americana ("uma classe trabalhadora livre, que não era dona de terra nem estava envolvida na produção agrícola, cujo crescimento criou a demanda por bens”, p. 410) aparece como um resultado indireto da própria escravidão.

A expansão produtiva incentivou a imigração massiva de mão de obra livre europeia a partir da década de 1840, ampliando ainda mais a distância entre Norte e Sul. O "domínio continuado do Sul sobre 
o processo político” (p. 421) é assim, de acordo com Baptist, enfraquecido por um norte crescentemente mais populoso e independente da economia algodoeira. O impacto disso pavimentou, por um lado, a reação do Sul escravista na defesa de suas prerrogativas "federativas" e a aventura da secessão que teve a Guerra Civil como consequência. Mas foram as transformações nas circunstâncias econômicas e políticas que permitiram as mudanças na opinião pública ianque sobre o alcance das políticas sulistas. Uma posição mais radical e independente com relação à questão da escravidão acaba sendo o resultado indireto dessas mudanças.

Na última década antebellum, o destino dos quase quatro milhões de pessoas escravizadas alimentava o debate sobre o futuro do país e de sua expansão. Mesmo o apoio do Norte à guerra com o México e à conquista territorial não foi acompanhado do apoio à expansão da escravidão. O tratado de Guadaloupe-Hidalgo, em 1848, estabeleceu as fronteiras definitivas com o México, incorporando os territórios até o litoral do Pacífico, mas não garantiu a expansão ilimitada das fronteiras da escravidão, que permaneceram disputadas até as vésperas da guerra.

Ainda assim, o embate pelas prerrogativas expansionistas da escravidão foi realizado no campo jurídico, em uma tentativa, bem sucedida até a Guerra Civil, de criar uma jurisprudência que garantisse os direitos adquiridos dos senhores de escravos de usar e dispor de suas propriedades, inclusive removê-las e resgatá-las para além das fronteiras dos estados escravistas. Alguns dos dispositivos legais de então (como a ideia do "devido processo substantivo", que impedia a aprovação de leis que contrariassem o direito de propriedade) sobreviveriam à própria escravidão e foram funcionais nas justificativas do capitalismo desregulamentado da Gilded Age (Era Dourada, c. 1870-c. 1900), ajudando a moldar "a economia política dos Estados Unidos de uma maneira contínua” (p. 425).

O décimo e último capítulo, "Braços”, debruça-se sobre o contexto e as circunstâncias que levaram à deflagração da guerra. A emergência de atores importantes no campo antiescravista (desde o intelectual negro Frederick Douglass 
ao abolicionista branco radical John Brown, passando por Abraham Lincoln) é conectada à emergência de um campo político que permitia, pela primeira vez, desarticular o sistema que havia "vinculado os interesses nacionais à expansão da escravidão" (p. 445). Em contraste, o campo de defesa da instituição escravista continuou a prosperar, sustentado pela produtividade do algodão produzido pelos escravizados, e pela convicção dos seus próprios ideólogos, que "se viam como pessoas modernas que administravam um setor altamente bem-sucedido e inovador de uma economia mundial crescendo mais rápido do que nunca” (p. 445).

Edward Baptist argumenta convincentemente que a escravidão nos Estados Unidos não apresentava, em sua última década de existência, sinal de que perdesse força. Ao contrário, mostra que é uma ilusão imaginar que a escravidão estava condenada ao desaparecimento nos EUA por força do avanço da "modernidade" capitalista: a “modernidade” da escravidão era possível de ser pensada graças ao seu profundo entrelaçamento com a prosperidade do país como um todo. Afinal, a propriedade escrava representava um quinto da riqueza nacional em 1850, os preços dos corpos escravizados não paravam de subir, o tráfico interno ia a todo vapor e a emergência de uma nova "ecologia financeira" depois da crise de endividamento dos anos 1840 havia tornado mais modernas e controláveis as receitas oriundas do comércio e da propriedade em escravos que se entrelaçavam ao mercado de capitais. A elite norteamericana, não apenas do Sul mas também os barões das finanças de Nova York, sonhava com a anexação de Cuba, a expansão da fronteira produtiva escravista e o cumprimento do “Destino Manifesto”, para a frustração, nas palavras de Baptist, dos "planos dos Whigs, dos abolicionistas, dos negros livres e de todos os outros" que as elites sulistas "desprezavam coletivamente” (p. 458). Os escravocratas prosperavam protegidos por um ambiente legal favorável, garantidos por instituições financeiras renovadas e funcionais e suficientemente seguros de si para produzir seus próprios argumentos ideológicos sobre a superioridade moral e econômica da escravidão. 
Afirmando a competência dos poderes locais ("autodeterminação”) para definir a questão escravista e negando a jurisdição do governo central sobre o tema, decisões notáveis da Suprema Corte (Dred Scott versus Sanford, em 1857,1 sendo a mais notória delas) marcaram o avanço da proteção legal à escravidão, definindo a queda de braço entre as forças políticas que se confrontariam na Guerra Civil. A defesa da escravidão era também um ataque à cidadania negra em geral e colocava em pauta o sentido geral que a palavra "liberdade" poderia continuar a ter no país. Essas foram questões que redefiniram o quadro político-partidário dos EUA nos anos 1850, tornando o contencioso em

1 Dred Scott versus Sanford foi uma célebre decisão da Suprema Corte americana que, em 1857, examinou o caso proposto por Dred Scott, um homem que havia sido escravizado e que entrou com um processo de liberdade para si, sua mulher e suas duas filhas, argumentando que haviam vivido por quatro anos nos estados norte-americanos de Illinois e Wisconsin, onde a propriedade de escravos era ilegal. A decisão da Suprema Corte, contrária a Scott, estabeleceu a jurisprudência de que nenhuma pessoa afro-americana poderia reclamar direitos de cidadania nos Estados Unidos, e que era inconstitucional privar o proprietário de Scott de seus bens. torno do futuro da escravidão o principal ponto de discórdia, desenhando com maior clareza os limites das forças políticas, com a emergência no Norte do Partido Republicano, no fim dos anos 1850, e tornando o Partido Democrata a expressão política principal dos interesses do Sul.

Baptist sublinha o papel da violenta Guerra Civil (mais de seiscentos mil mortos) como elemento definidor na mudança de rumo dessa história. Ele mostra, contudo, que o conflito não foi travado em nome da alma americana por um Norte virtuoso e avesso à escravidão, mas foi antes uma disputa entre duas versões da dominação branca sobre a "melhor maneira de manter o curso do algodão e das receitas financeiras fluindo: manter a escravidão dentro de suas fronteiras usuais ou permitir que ela consumisse ainda mais fronteiras geográficas” (p. 25). A aventura da secessão e da guerra teria sido assim uma aposta do Sul, que acabou perdendo não por causa das debilidades da escravidão, mas pela própria dinâmica do confronto e pela ação decisiva dos escravizados. Após a Proclamação de Emancipação de Lincoln de 1862, que colocou em 
pauta o fim da escravidão nos estados separatistas, foi como se tivessem "destrancado a porta" que "os afro-americanos forçariam até abri-la completamente" (p. 510). Com a Guerra Civil, o engajamento dos afro-americanos levou ao desfecho radical de uma abolição completa, ao invés da paz negociada que os confederados, liderados por Jefferson Davis, acabaram por desejar e que poderia atender à opinião branca do Norte (p. 512).

A versão - que se tornou quase dominante no pós-guerra - de que os confederados haviam se revoltado em nome do "princípio constitucional abstrato" dos "direitos dos estados" é desmascarada por Baptist como uma mentira deslavada: era o futuro da escravidão que estava em jogo para os sulistas, que viram a movimentação dos "black republicans" (como chamavam ironicamente os seus adversários) e a escolha de Lincoln como candidato como uma opção, para eles inaceitável, pelo compromisso com a "igualdade entre as raças branca e preta” (p. 498). Uma convicção que também reverberava junto à população branca sulista que não possuía escravos, mas que se sentia ameaçada pela extensão de suas prerrogativas à população negra.

A conclusão do livro (intitulada “Posfácio. O Cadáver: 1861-1937”) debruça-se sobre o conflito em si e suas consequências econômicas e políticas, que não apenas redefiniram o lugar do Sul no pós-guerra, mas também teve efeitos globais, com a quebra da produção algodoeira possibilitando a participação competitiva de produtores na África Ocidental, no Egito e mesmo no Brasil no mercado do algodão. Mais importante para Baptist, o engajamento afro-americano no lado da União na Guerra Civil não apenas foi o ponto de inflexão da abolição completa, mas também lançou "as bases para a reivindicação dos afro-americanos à identidade cívica e política em uma sociedade pós-escravidão" (p. 512). O livro conclui passando rapidamente pela Reconstrução radical e seu fim melancólico, a partir de 1873, quando o apoio à expansão da cidadania aos negros sucumbiu diante dos compromissos entre a elite sulista e a “América Branca” do norte, abrindo caminho para o Jim Crow, ou seja, 
a legalização da discriminação racial.

Localmente, o resultado mais profundo da debacle foi a pobreza generalizada: a colheita do algodão nunca recuperaria a produtividade que teve durante a escravidão e a prosperidade havia desvanecido até mesmo para boa parte da população branca rural. Ainda assim, a desigualdade estrutural impactou com mais força a população afro-americana, e foi seu efeito mais persistente: enquanto o que sobrou do legado da acumulação escravista antes de 1861 permaneceu nas mãos da elite branca, a pobreza material foi o quinhão dos ex-escravizados, até bem depois do New Deal na década de 1930.

A herança da escravidão foi, entretanto, igualmente duradoura em outros campos, ajudando a forjar os paradigmas legais e as políticas públicas que marcaram a vida civil no pós-emancipação. Baptist argumenta que a experiência de luta contra a escravidão, o abolicionismo e o engajamento na guerra ajudaram a forjar a unidade política da consciência afro-americana, com impacto de longo prazo. Os afro-americanos foram capazes de inserir sua "reinvidicação por cidadania na Constituição" dos Estados Unidos e, mais do que isso, nas palavras de Baptist, "haviam criado, com os aliados brancos, na forma do abolicionismo, o modelo ideológico da dissidência americana, do progressismo e da fé na mudança social que, buscada com um zelo religioso, poderia tornar a república norte-americana mais fiel ao seu eu ideal” (p. 526).

Os alicerces de A metade que nunca foi contada repousam em duas teses, fartamente discutidas no livro: a primeira delas é de que a modernidade capitalista e escravidão nunca foram incompatíveis, mas se reforçaram mutuamente no boom da economia da primeira revolução industrial. A segunda tese é a de que a inovação principal do engenho de destruição criativa do capitalismo norte-americano está na violência sem precedentes com que a escravidão foi utilizada para extrair o máximo de produtividade do seu principal insumo, o algodão. As duas teses são amarradas pela proposição, declarada na introdução do livro, de que "a expansão da escravidão deu forma a cada aspecto crucial da economia e da política da nova nação” (p. 19). 
O livro não pretende englobar os duzentos e cinquenta anos que separam a chegada dos primeiros escravizados na Virgínia, em 1619, e a promulgação da $13^{\mathrm{a}}$ emenda que aboliu a escravidão dos EUA, em 1865, nem sugere que o regime escravocrata e a plantation escravista tenham se mantido imutáveis ao longo desse tempo. Ao contrário, o autor se debruça sobre as enormes mudanças no funcionamento e na dinâmica da escravização no país, que foram identificadas como uma “Segunda Escravidão”, segundo o termo cunhado pelo sociólogo Dale Tomich. ${ }^{2}$ O conceito, que é amplamente utilizado no livro, abarca as transformações da instituição escravista cujo apogeu coincidiu, e interagiu fortemente, com a implantação e expansão do capitalismo industrial entre o final do século XVIII e as últimas abolições no continente americano, no sul dos Estados Unidos (1865), em Cuba (1886) e no Brasil (1888). O livro de Baptist se inscreve, assim, em um campo historiográfico relativamente recente, mas que

2 Dale Tomich, Sob o prisma da escravidão: trabalho, capital e economia mundial, São Paulo: Edusp, 2011. produziu resultados notáveis, não apenas nos Estados Unidos, e que é identificado com a "nova história do capitalismo". ${ }^{3}$

Baptist lembra o quanto a narrativa que afirmava que a escravidão estava destinada a desaparecer com a modernidade capitalista e o trabalho livre - uma narrativa compartilhada por muitos contemporâneos da escravidão, mas também por boa parte da historiografia ignorava o entrelaçamento entre essa mesma "modernidade" e a renovação da escravidão. Atualizando um argumento não desconhecido por estudos clássicos sobre a escravidão, ele confronta sobretudo o mito da baixa produtividade do trabalho escravo em comparação ao trabalho assalariado, e a ideia de que a escravidão era avessa à inovação e, portanto, incompatível

3 Exemplos dessa historiografia são o livro de Calvin Schermerhorn, The Business of Slavery and the Rise of American Capitalism, 1815-1860, New Haven: Yale University Press, 2015, e, entre outros: Sven Beckert e Seth Rockman (orgs.), Slavery's Capitalism: A New History of American Economican Development, Filadélfia: University of Pennsylvannia Press, 2016; e Rafael Bivar Marquese e Ricardo Salles (orgs.), Escravidão $e$ capitalismo histórico no século XIX: Cuba, Brasil, Estados Unidos, Rio de Janeiro: Civilização Brasileira, 2016. 
com a adaptabilidade, inventividade e a disposição para assumir riscos que caracterizariam o etos capitalista moderno. O autor faz um grande trabalho ao demolir esses mitos de modo convincente e documentado, ao mesmo tempo que ilustra de modo eloquente como a escravidão estava intimamente associada ao "livre mercado", dando um sentido concreto à imagem do "instinto assassino" que é fonte de orgulho do "livre empreendedor" norte-americano.

Baptist abre ainda outras frentes de embate com a historiografia. As histórias da escravidão focadas nas experiências de "resistência assertiva” (p. 15) dos escravizados contra o sistema teriam dado, na sua opinião, a falsa impressão de que a "agência” dos escravos foi de fato eficaz em enfraquecer o sistema, resistir à exploração e, em última instância, torná-lo mais suportável, permitindo que criassem uma "cultura negra independente". Ele denuncia o que julga ser a "simetria parcial” entre essas histórias e as edulcoradas "memórias das fazendas da época posterior à guerra civil, as quais retratavam senhores gentis que mantinham a escravidão como um esforço sem fins lucrativos cujo objetivo era civilizar os africanos" (p. 15). Para Baptist, as histórias focadas na resistência escrava subestimam o caráter violento e explorador da escravidão. Sua crítica volta-se a um fundamento ainda mais profundo dessa historiografia em suas raízes liberais: a convicção subjacente de que o grande pecado da escravidão teria sido o de "negar aos afro-americanos escravizados os direitos e a subjetividade liberais dos cidadãos modernos" (p. 16). Baptist quer retirar a crítica à escravidão do plano subjetivo e imaterial da "liberdade" aviltada e devolvê-la ao plano da materialidade das suas relações de produção: o regime de horror, brutalidade, exploração e sadismo da escravidão foi montado como um mecanismo de produzir lucro através da construção de um império de commodities.

A perspectiva explicitamente “materialista” de Baptist pretende recolocar no eixo central da explicação as forças produtivas do capitalismo na remodelação do mundo moderno. Baptist se debruça sobre a realidade material da escravidão, concretizada na exploração extrema do trabalho e 
da objetificação das pessoas escravizadas: mãos, braços, costas, cabeças, línguas. Na mesma trilha, ele faz a escolha (também política) de não utilizar, em seu livro, eufemismos para descrever o que acontecia nos campos de algodão: "tortura” substitui "castigo" para descrever a violência continuada nos "campos de trabalho" (que tomam o lugar das "plantações/ plantations”), e assim por diante. É também uma escolha deliberada de Baptist mergulhar no regime de sadismo "racional" que predominava na "segunda escravidão".

A "história evocativa" (nota da p. 28) de Baptist controla a narrativa, restabelecendo a primazia das forças anônimas, estruturais, que deram forma à vida e às experiências dos atores sociais, ao mesmo tempo que coloca em seu centro histórias de sofrimento, de exploração e da alienação física e psicológica dos escravizados. Em seu livro as relações sociais produzidas pela escravidão são o resultado direto da emergência desse novo quadro de relações de produção que conectam, inexoravelmente, o destino da escravidão às forças crescentes do capitalismo global. A “evocação” que o livro busca traz ao centro do palco o modo como os homens e mulheres escravizados viram suas expectativas e possibilidades moldadas pelos processos que marcaram o período. $\mathrm{O}$ mundo da escravidão que a narrativa desenha é, invariavelmente, sombrio e desesperançado, um quadro de horror desenhado nos documentos dos plantadores, nas narrativas e nos testemunhos da última geração de escravizados. Há pouco lugar, nessa história, para a negociação na arena da escravidão, e mesmo para a resistência consequente. É a eficácia acachapante e "moderna" desse regime que ocupa o lugar principal na interpretação do historiador.

A desconfiança da historiografia que coloca o protagonismo consciente (agency) dos escravizados em primeiro plano é o elemento definidor das escolhas retóricas e interpretativas de Baptist, mas também evidencia alguns dos limites do seu argumento. Não se trata de tomar emprestadas as críticas feitas a este livro pelos historiadores econômicos, que consideraram insuficientemente demonstrada sua tese sobre o papel determinante da economia do Sul sobre o desenvolvimento industrial do Norte dos 
Estados Unidos. ${ }^{4}$ Baptist é eloquente ao construir seu argumento de que a escravidão era mais eficiente do que o trabalho livre para a produção da matéria-prima para a indústria. O sistema era adaptável, renovava-se constantemente e havia sido uma força determinante no refinamento dos mecanismos de crédito que impulsionaram o capitalismo dali em diante. Mesmo as crises sucessivas de produção e crédito acabaram funcionando para reorganizar e aperfeiçoar o sistema. Todos os fios convergem para o mesmo lugar. É um quadro dramático e coerente.

Mas essa insistência no caráter sistêmico e coerente da "máquina" escravista torna o livro de Baptist, de um ponto de vista da história social da escravidão, menos convincente do que poderia ser. $\mathrm{O}$ primeiro risco em que ele incorre - e paira sobre vários capítulos - é o de tomar os homens e mulheres escravizados apenas como fatores de produção cujas vidas subjetivas e complexas só se manifestam nas suas formas mais desesperadas. Isso é

4 Ver, por exemplo, a resenha de Stanley Engerman sobre os livros de Edward Baptist e de Calvin Schermerhorn em Journal of Economic Literature, v. 55, n. 2 (2017), pp. 637-643 dof. problemático sobretudo quando Baptist tenta lidar com uma questão central para o livro, que é a pergunta sobre como um sistema tão bem azeitado foi desmontado de modo tão decisivo. As vozes dissidentes aparecem aqui e ali (os abolicionistas e os que conseguiram escapar à escravização), bem como as experiências que apontam para alternativas ao sistema, mas a sua eficácia não parece ser das melhores e seu alcance limitado. Nesse sentido, mesmo a emergência de uma forte oposição no Norte à expansão da escravidão não parece muito substancial, nem destinada ao sucesso. A Guerra Civil, que Baptist associa ao esforço consciente das elites algodoeiras para defender não apenas a manutenção, mas a expansão da escravidão nos novos estados do oeste, aparece como o evento chave. O conflito acontece, contudo, como um evento quase inexplicável: erro de cálculo das elites sulinas, que forçaram a mão na sua estratégia de perpetuar a escravidão e a supremacia branca, erro reforçado, afinal, pelo protagonismo dos escravizados para mudar os rumos da guerra. Contudo, e levando em conta o empenho constante do autor em definir como inúteis os esforços dos escravizados em escapar à máquina 
escravista do império do algodão, a destruição objetiva e subjetiva da individualidade daqueles, dos seus laços de família, de suas relações humanas mais básicas, o leitor fica sem entender como os escravizados acabaram por desempenhar um papel fundamental para pôr fim a seus tormentos.

O livro não nos permite entender sobre quais bases os escravizados não apenas estabeleceram a sua compreensão da guerra, mas sobretudo como se engajaram no novo quadro político do pós-emancipação, isto é, a chamada Reconstrução. A música, a dança e a religião aparecem brevemente no livro como pontos de fuga, espaços de autonomia individual e integração social que escapam pelas poucas brechas deixadas pela segunda escravidão. Como essas experiências ligam-se ao momento posterior, não está claro.

Será preciso procurar em algum outro lugar, que não é este livro, como aqueles homens e mulheres foram capazes de se mobilizar para construir uma cultura política consequente e duradoura, e capazes mesmo de uma contribuição única à cultura global "Uma das exportações culturais mais importantes da história mundial” (p. 271), escreve Baptist sobre a música afro-americana. Esse salto, real, não se concatena com a história de horror contada no livro. Será preciso buscar em outros estudos os meandros, as contradições e brechas do sistema, a riqueza das situações individuais irredutíveis ao quadro geral, para - sem perder a compreensão das dinâmicas estruturais - corrigir o quadro uniforme, coerente e sem saída que o livro de Baptist pinta.

Além da falsa questão de colocar-se como contraponto à historiografia que estudou com atenção e detalhe a vida social e cultural dos escravizados - que não se deixaram reduzir a uma expressão anônima das forças sociais e econômicas (trabalhos sem os quais o de Baptist não seria escrito), há outros aspectos do livro que merecem crítica.

Centrado no Deep South, o lócus da "segunda escravidão" norte-americana, Baptist acaba fazendo tabula rasa da experiência dos escravizados fora dessa fronteira, além da população - por menor que tenha sido de negros livres, cujas experiências não parecem contribuir nem para a 
luta contra a escravidão, nem para a formação de uma cultura política viável durante e após a Reconstrução. Sendo uma história da escravidão nos Estados Unidos, o livro também incorre frequentemente no erro de tomar a experiência norte-americana como uma unidade isolada: influência definidora sobre o mundo, mas impermeável ao que acontece fora de suas fronteiras. Embora discuta as conexões da escravidão norteamericana com os mercados e centros financeiros globais, leia-se europeus e sobretudo britânicos, quase não há menção à escravidão fora desse mundo. A visão estrita da "segunda escravidão" como um fenômeno absolutamente novo e estritamente amarrado à narrativa do capitalismo triunfante também manifesta em certa medida essa miopia historiográfica.

Se é verdade que a ideia de uma “segunda escravidão” tornou-se útil para revelar e compreender os elementos distintivos que marcaram os processos de escravização no século XIX e suas relações com as dinâmicas estruturais do capitalismo, a redução da história da escravidão no período a essa dinâmica histórica exclusiva corre o risco real de tornar invisíveis as ambiguidades do sistema, bem como os modos distintos com que se expressou em diferentes contextos (não apenas nas outras partes do continente americano onde a escravidão persistiu, mas no próprio contexto estadunidense). Decretar, por exemplo, a "morte da velha escravidão" invocando a revolução no Haiti é continuar contando apenas uma parte (a "metade”) da história complexa da escravidão no continente, e só faz sentido dentro de uma visão estritamente norteamericana do seu desenvolvimento. Essa visão apenas marcada pela experiência do sul dos Estados Unidos apresenta limites sobretudo para quem se preocupa em pensar a história da escravidão de um ponto de vista comparativo ou conectado. O quadro reconstruído por Baptist tem, assim, um impacto limitado para o entendimento da escravidão alhures (mesmo Cuba e, talvez sobretudo, o Brasil), pois se as condições específicas da escravização ligada ao mercado de commodities pode ser válida para pensar a fronteira de expansão do cultivo do café no século XIX, é certamente insuficiente para pensar outras áreas onde a escravidão 
manteve sua importância sem conexão direta com os grandes fluxos comerciais internacionais.

Considerando que um dos pontos de chegada do livro é argumentar que foi a experiência da escravidão e do seu fim no Sul que forjou a cultura política afro-americana, com impactos de longo prazo, é também notável a ausência de menção às lutas anticoloniais fora dos Estados Unidos que influenciaram, por exemplo, os movimentos pelos direitos civis. Esses aparecem, no argumento de Baptist, como exclusivamente tributários da experiência única e singular dos afro-norte-americanos do Sul. Por essa e outras, Baptist arrisca a praticar uma modalidade de "história global” que parte do protagonismo norte-americano e nele se encerra. Sua ênfase na expressão norteamericana da "segunda escravidão", a modernidade capitalista e a eficácia incontrolável e sádica dos empreendedores escravistas aparecem como forças históricas irresistíveis, avatares bestiais do destino manifesto norteamericano, que às vezes funciona, de um modo um tanto perturbador, como uma celebração macabra da inevitabilidade do capitalismo racial e da supremacia norte-americana no planeta Terra.

A despeito dessas críticas, os méritos de A metade que nunca foi contada são numerosos. Trata-se de um livro descritivo, às vezes repetitivo, e frequentemente cru e direto na sua descrição de um mundo opressivo e violento. Mas é também enciclopédico, sintético e abundantemente ilustrativo, além de exemplo importante de uma historiografia rica e raramente traduzida em português. Mesmo com os problemas eventuais de tradução - com erros pontuais e pecando amiúde pelo excesso de literalidade - o livro está destinado a ser uma referência incontornável para quem pretenda compreender a história do "sucesso" norte-americano e o papel que a escravidão ocupou nela.

\section{Henrique Espada Lima (D)}

Universidade Federal de Santa Catarina 